
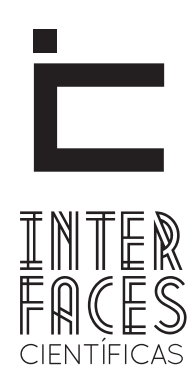

DIREITO

\title{
A IMPORTÂNCIA DA APLICAÇÃO DE UM PROGRAMA DE COMPLIANCE EM ADEQUAÇÃO ALEl 12.846/2013.
}

THE IMPORTANCE OF THE APPLICATION OF A COMPLIANCE PROGRAM IN ACCORDANCE WITH LAW 12.846 / 2013. LA IMPORTANCIA DE LA APLICACIÓN DE UN PROGRAMA DE CUMPLIMIENTO NORMATIVO EN ADECUACIÓN A LA LEY 12.846/2013.

\section{RESUMO}

Este artigo objetivou apresentar a importância na implantação de um programa de compliance, que significa um conjunto de mecanismos e regras internas e externas para a conformidade nos contratos e nas transações com o governo, respaldado pela Lei $12.846 / 2013$, regulamentada pelo Decreto $8.420 / 2015$. Mostrando os pontos necessários para implantação de um programa de conformidade, bem como a utilidade de se criar uma cultura de procedimentos a ser seguida dentro das instituições, visando evitar atos lesivos e de corrupção, danificando assim a imagem das instituições perante o mercado. Para tal fim, o critério metodológico aplicado, para verificar esse ensaio, consiste no método hipotético-dedutivo, começando em uma análise bibliográfica e documental com fundamento na biografia especializada em compliance.

\section{PALAVRAS-CHAVE}

Compliance; Programa Conformidade; Procedimentos 


\section{ABSTRACT}

This article aims to present the importance in the implementation of a compliance program, which means a set of internal and external mechanisms and rules for compliance in contracts and transactions with the government, supported by Law 12.846 / 2013 regulated by Decree 8.420 / 2015. It shows the necessary points for the implementation of a compliance program as well as the usefulness of creating a culture of procedures to be followed within the institutions in order to avoid harmful acts and corruption, thus damaging the

\section{RESUMEN}

Este artículo objetivó presentar la importancia en la implantación de un programa de cumplimiento, que significa un conjunto de mecanismos y reglas internas y externas para la conformidad en los contratos y en las transacciones con el gobierno, respaldado por la Ley $12.846 / 2013$, regulada por el Decreto $8.420 / 2015$, regulada por el Decreto 8.420/2015. En el caso de los países de la Unión Europea, los países de la Unión Europea (UE) y los Estados miembros de la Unión Europea (UE). A tal fin, el criterio metodo- institutions' image in the market. To that end, the methodological criterion applied to verify this test consists of the hypothetical-deductive method, starting with a bibliographic and documentary analysis based on specialized biography in compliance.

\section{KEYWORDS}

Compliance. Compliance Program. Procedures lógico aplicado, para verificar ese ensayo, consiste en el método hipotético-deductivo, comenzando en un análisis bibliográfico y documental con base en la biografía especializada en cumplimiento normativo.

\section{PALABRAS CLAVE}

Compliance; Cumplimiento Normativo; Programa Conformidad; Procedimientos 


\section{INTRODUÇÃ̃O}

0 presente trabalho se justifica pela necessidade de se criar mecanismos jurídicos para combater os atos de corrupção nas instituições e diminuir comportamentos lesivos e seus impactos negativos na atividade empresarial econômica, nos negócios público privado, constituindo-se método hipotético-dedutivo.

Compliance pode ser delineado como uma série de critérios a serem observados e cumpridos no âmbito interno e externo de uma entidade, seja ela pública ou privada e ações a serem praticados por um determinado responsável pela operação, planejamento como também o setor financeiro, com a finalidade de anteceder ou reduzir os riscos de transgressões às leis que controlam o seu funcionamento; e nos casos em que um delito for detectado, ter a força de reação pontual e rápida para eliminar o problema, preservando assim a imagem da entidade em razão do mercado.

Por meio de um programa de compliance as relações público-privadas procuram promover uma cultura corporativa de cumprimento das leis e regulamentos, alinhado com a legislação vigente, bem como as normas internas e externas, ajustando seu comprometimento com as regras jurídicas para tratativas com o poder público, objetivando elaborar padrões e costumes, definidos em um código de ética e conduta efetivo.

Em sua totalidade, o programa de compliance, vem ganhando força no Brasil, depois da operação lava jato, na qual veio à tona uma infinidade de práticas corruptas, envolvendo a alta direção de várias empresas estatais e privadas, com isso causando atos lesivos e prejuízos financeiros aos cofres públicos.

Nesse sentido, a problemática do presente estudo, consiste em obter comcompliance, como novo instrumento efetivo de combate a corrupção nos contratos com o Poder Público. Nesse cenário, nasceu a necessidade de adequação, em relação às formas e regras para se contratar com o Estado. Desse modo, o Decreto Federal 8.420/2015 que regulamenta a Lei 12.846/2013, aborda a necessidade de um programa de integridade efetivo.
Nessa conjuntura, um robusto e efetivo programa de integridade se torna um grande desafio no que diz respeito às normas e legislação vigente, no enfrentamento e nas medidas para se antecipar atos de corrupção. Portanto, buscou-se reunir conhecimentos, com o propósito de responder como o desenvolvimento de políticas e controles jurídicos internos das instituições se adequam às exigências da Lei $n^{\circ} 12.846 / 2013$, na implantação de um programa de integridade eficaz, dado que, para o Estado, os esforços são no sentido de evitar atos lesivos e para as empresas que celebram transações com o Governo, é estar em conformidade com a legislação, para poder contratar.

Tem como objetivo apresentar como o desenvolvimento de políticas e controles jurídicos internos das instituições na implantação de um programa de compliance, como nova ferramenta para reduzir corrupção, e atos lesivos, nos negócios jurídicos, combatendo as fraudes; com um planejamento programado para a contratação com o Poder Público, demonstrando os benefícios do programa de integridade para fomentar uma cultura de ética nas empresas e analisar os requisitos indispensáveis para a efetivação de um programa de conformidade.

O objeto deste estudo está delineado nos dispositivos da Lei 12.846/2013, que institui a responsabilização de empresas na esfera civil e administrativa quando praticado atos de corrupção junto a administração Pública.

O presente artigo foi concebido por meio de uma pesquisa bibliográfica em literatura especializada a respeito do tema, foram interpeladas legislações sobre o programa de integridade, na Lei 12.846/2013 e em outros códigos do ordenamento jurídico que regulam o Direito empresarial econômico e seus mecanismos frente as empresas e o Governo.

Devido à implantação de um programa de compliance, observando a transparência ao contratar, levanta-se aqui a hipótese de que o Governo estará mais respaldado, na seara jurídica, para enfrentar por meio de normatização interna e externa, visando o benefício da dimi- 
nuição de possíveis atos de corrupção, cometidos por seus agentes e terceiros que contratam com ele, atendendo assim o regulamento da Lei 12.846/2013.

\section{CONHECENDO 0 PROGRAMA DE COMPLIANCE}

Pode-se dizer que compliance é um instrumento para consolidar o cumprimento de normas internas e externas consoantes com as conformidades jurídicas e de condutas, pertencentes a uma instituição, seja ela pública ou privada, procurando equilibrar a legislação, as práticas e procedimentos das organizações. Nesse contexto pode-se observar que o compliance é um processo constituído de forma global e integrado aos diversos setores da organização, com o papel de impactar os diversos pontos de operação das organizações (CICCO, 2008).

0 mais preocupante, contudo, é constatar que a importância do compliance nas instituições é um crescente, devido à necessidade de ter uma proteção da imagem e da reputação das instituições, em face do mercado em que atuam. Fica evidente a necessidade de introduzir nas políticas das instituições a cultura do compliance, visando aprimorar os controles internos e os externos, com esforços de todas as equipes nos diversos setores das entidades para poder se alcançar a efetividade nas operações comerciais.

De acordo com (CICCO, 2008), para obter uma eficiência em um programa de compliance é apropriado que toda a organização seja engajada, de forma a se envolver com as normatizações pertinentes. Criando um ambiente de empenho em alcançar as melhores práticas, buscando estar alinhado com as legislações, regras internas das instituições, mantendo assim um afinco nas condutas de trabalho.

Conforme explicado acima, pode-se dizer que para ter um efetivo desempenho nas políticas que regulamentam as boas práticas na implantação de um programa de compliance, o colaborador tem que verdadeiramente estar receptivo a novas culturas de regras e procedimentos. Visando, assim, melhorar o universo em que se trabalha. Assim, ingressando em uma meIhor prevenção de determinados atos, que podem ser lesivos às instituições, com ou sem dolo, que podem se enquadrar em ações de corrupção, previstas no artigo $5^{\circ}$ da lei $12.846 / 2013$.

Conforme verificado por Mendes e Carvalho (2017), com o intuito de forjar a efetivação dos procedimentos de um programa de compliance, para que os mesmos se tornem requisitos essenciais na cultura da legislação interna corporativa. 0 autor deixa clara a necessidade de fomentar esses hábitos como princípios culturais, para adotar uma melhor diligência, na prevenção de infrações danosa a empresa.

Trata-se, inegavelmente, de uma indicação de que o objetivo não é excluir definitivamente os casos de atos ilícitos que intercorrem nas instituições; seria um erro, porém, atribuir de forma absoluta à diminuição da incidência com que estes ocorram. Assim, reveste-se de particular importância ter uma resposta rápida e adequada, na medida correta, para os casos concretos identificados. Sob essa ótica, ganha particular relevância a implementação de regras internas e um canal de comunicação eficiente, com a alta direção, a fim de ter um meio de comunicação ativo para a identificação de problemas ligados a corrupção.

0 autor deixa claro, em seu livro Compliance: concorrência e combate à corrupção, porque é bastante concreta a implantação de um programa de compliance, como promoção no sentido de estimular novos comportamentos nas empresas. Nesse contexto, em que segue com o mesmo fulcro o autor Francisco de Cicco (2008, p. 5) “A maneira como uma organização trata o compliance deve ser modelada por seus valores principais e por padrões éticos”. Então, é preciso aproveitar para se desenvolver normas internas, de maneira a enriquecer a coletividade da empresa.

Tal hipótese é particularmente forte, pois a legislação brasileira está inclinada a estimular esse tipo de comprometimento. Certamente, se trata de uma tendência nacional em que o Brasil está avançando e tomando como preâmbulo a Lei 12.846/2013.

Conforme explicado acima, ora, em tese, os benefícios para a implantação de um programa de compliance, é a criação de ferramentas para desenvolver melhores práticas e condutas no corpo operacional, produtivo e de plane- 
jamento das entidades. Nesse ponto, a Lei 12.846/2013, busca a implantação dos programas de conformidade em seu artigo $7^{\circ}$, VIII. Caso contrário, pode haver sanções por desvio de conduta dos agentes integrantes do corpo de colaboradores e da alta administração.

Não se trata de forçar, coagir ou constranger os colaboradores; lamentavelmente, pode haver interpretações equivocadas na comunicação. É importante considerar que estabelecer cronogramas para a implantação do programa é fundamental, seja porque vai se observar uma previsão orçamentária, seja nesse caso para ter o planejamento tributário e financeiro; por exemplo, tendo a empresa todas as suas despesas mensais contabilizadas. É pertinente trazer à baila esses dados, que se mostram de suma importância para o planejamento das empresas.

Os funcionários devem ser encorajados a responder e a relatar violações da lei e de outros incidentes não-compliance, e a ver o relato como uma ação positiva e não ameaçadora. As obrigações de relato devem ser claramente definidas na política e nos procedimentos de compliance da organização e reforçadas através de outros métodos, tais como reforço dos gerentes durante seu trabalho do dia-a-dia com os funcionários. (CICCO, 2008, p. 31).

O autor deixa claro que, o planejamento dos canais de comunicação deve ter a finalidade de estimular de forma direta os funcionários a interagirem, apontando ilicitudes e atos fraudulentos cometidos pelos superiores hierarquicamente e também pelos próprios funcionários. Esse canal de comunicação por meio de relatos dos próprios colaboradores é um dos pontos fundamentais previstos nas normas e controles internos das instituições.

\section{EXIGENCIA LEGAL DO PROGRAMA DE CONFORMIDADE PREVISTO NA LEI 12.846/2013 E SEUS CÓDIGOS ACESSÓRIOS}

É importante ressaltar, a criação do regulamento jurídico que dispõe sobre as regras de combate a cor- rupção, dispostas ao longo da Lei 12.846/2013, em que o legislador estruturou em seu artigo $7^{\circ}$, inciso VIII, a previsão de métodos de integridade; mas, em cima disso, se observam, em outras cártulas do ordenamento nacional, tais como o Decreto 8.420/2015, que dispõe sobre responsabilização de pessoas jurídicas pela prática de atos contra a administração pública; o Decreto $8.945 / 2016$ que guarda a normatização sobre o estatuto jurídico das empresas públicas, a Lei 13.303/2015, que dispõe sobre as empresas públicas, as sociedades de economia mista, bem como todas as subsidiárias que operam com ela, tendo uma capilaridade bastante vasta no que diz respeito à responsabilização.

De forma objetiva, por ações e condutas de corrupção, finalmente, uma diretriz que vem harmonizar os procedimentos internos e externos com punições administrativas e também na seara civil de forma adequada a cada situação (PESTANA, 2016). Ora, encontrou-se um parâmetro robusto para confrontar a corrupção; nesse sentido, as instituições ganham força contra posturas e feitos ilícitos. Essa versão não é a única pela qual cabe dizer que a imagem das instituições fica mais assegurada com o programa de integridade, desse modo, resguardando o risco de impactos negativos à imagem da empresa.

Na opinião de Pestana (2016), pode-se dizer que o diploma 12.846/2013, traz uma riqueza de situações possíveis que podem alvejar diversas pessoas jurídicas envolvidas em corrupção. Neste contexto, fica claro que em seu artigo $10^{\circ}$, a carta anticorrupção apura as responsabilidades em caso de envolvimento de pessoas jurídicas em situações de corrupção. 0 mais importante, contudo, é constatar a responsabilidade solidária. Não é exagero afirmar que isso é um fator de constrangimento para os envolvidos. Em todo esse processo, ocorre uma severa imputação de responsabilidade objetiva aos implicados nesses atos de corrupção.

Conforme explicado acima, é importante salientar que a responsabilização se procede de forma mais intensa, mas, em cima disso, ainda pode ter a sanção penal, em casos de crimes comprovados. Finalmente, o processo administrativo de responsabilização tem bastante magnitude. 0 Ministério Público também 
se faz presente, tomando conhecimento dos autos do processo administrativo como consta do artigo $15^{\circ}$, nesse sentido, a Lei 12.842/13 é bastante robusta. Essa versão não é a única pela qual cabe dizer que a responsabilização de pessoas envolvidas em corrupção está mais sólida.

Conforme verificado em Viana e Simão (2017), trata-se inegavelmente de uma responsabilização em dois aspectos distintos; uma no tocante à área administrativa e a outra para o ordenamento civil; o autor deixa claro que seria um erro, porém, atribuir caráter subjetivo à disciplina na Lei 12.846/2013. Assim, reveste-se de particular importância essa distinção dos setores que atingem a exigência da referida lei. Sob essa ótica, ganha particular relevância a distinção desses tipos de sanção, a civil e a administrativa.

Pode-se dizer que, no que tange à forma escrita da lei está nítida a previsão de sanções em duas esferas. Neste contexto, o legislador deixa claro que ao fim do processo administrativo, apuradas as responsabilidades, nada obsta a que os envolvidos sejam penalizados na seara jurídica. 0 mais importante, no entanto, é constatar que a responsabilização será aplicada. Não é exagero afirmar que essa previsão é importante para a segurança jurídica do processo. Assim, prevê a Lei 12.486/13, em seu artigo 18, "Na esfera administrativa, a responsabilidade da pessoa jurídica não afasta a possibilidade de sua responsabilização na esfera judicial” (BRASIL, 2013).

\section{PAPEL DO PROGRAMA DE COMPLIANCE EM RELAÇÃO AS RESPONSABILIDADES JURÍDICAS}

É importante ressaltar que o processo administrativo de responsabilidades na Lei $12.486 / 2013$, conforme expressa o Art. $5^{\circ}$ dessa lei, que precisa aquilo que é ato lesivo, caberá à autoridade superior de cada órgão, bem como aos chefes dos Poderes Administrativo, Legislativo e Judiciário; por exemplo, um agente público estadual, será julgado administrativamente pelo seu Poder respectivo; mas, em cima disso, também funcionam as outras esferas de Poder e no que diz respeito à pessoa física, a qual pode sofrer todas as sanções da pessoa jurídica, se provocar confusão patrimonial, ocultando e dissimulando patrimônio, no decorrer do processo administrativo.

Ora, esse processo é parte fundamental para se apurar tudo que aconteceu; nesse sentido, serão identificadas as responsabilidades. Essa versão não é a única pela qual cabe dizer que será analisado todo procedimento, resguardado nos artigos $8^{\circ}$ até o artigo $15^{\circ}$.

De acordo com o Art. 14, da Lei 12.846/2013, que ordena acerca da desconsideração da responsabilidade jurídica, caso haja trapaça dos investigados:

\begin{abstract}
Art. 14. A personalidade jurídica poderá ser desconsiderada sempre que utilizada com abuso do direito para facilitar, encobrir ou dissimular a prática dos atos ilícitos previstos nesta Lei ou para provocar confusão patrimonial, sendo estendidos todos os efeitos das sanções aplicadas à pessoa jurídica aos seus administradores e sócios com poderes de administração, observados o contraditório e a ampla defesa. (BRASIL, 2013, on-line).
\end{abstract}

Portanto, o legislador deixa claro o objetivo de inibir qualquer tipo de subterfúgio para burlar, enganar, ou dissimular, qualquer ato que venha a dificultar e até tentar encobrir participação em atos ilícitos do referido dispositivo. Esse é um ponto importante na hora de se apontar e determinar o programa de compliance para a alta diretoria.

Essa, porém, é uma tarefa que se observa nas atuações da polícia federal pertinente a investigações de lavagem de dinheiro. Vê-se, pois, que é uma manobra aplicada nos casos de sonegação de patrimônio, fiscal, evasão pecuniária e lavagem de dinheiro.

\section{CONTROLE DE RISCOS E PREVENÇ̃̃O DE ATOS ILICITOS LESIVOS.}

No quesito de prevenção contra a corrupção, impulsionando a vanguarda, os controles de riscos e as prevenções de atos ilícitos são um tema relativamente atual, em sede de normas e controles voltados para o Direito e suas regulações na tratativa entre empresas 
e Governo; os benefícios de instituir um programa de conformidade têm o objetivo de identificar e apontar áreas de atuação da empresa que eventualmente, tenham situações de fragilidade: além de que, esses controles da atuação dos colaboradores desenvolve indicadores, que contribuem para uma melhor gestão de risco; promovendo elementos para tomada de decisão em uma resposta mais célere, atendendo assim o que prevê o artigo $5^{\circ}$ da Lei 12.846/2013:

Art. 50 Constituem atos lesivos à administração pública, nacional ou estrangeira, para os fins desta Lei, todos aqueles praticados pelas pessoas jurídicas mencionadas no parágrafo único do art. 10, que atentem contra o patrimônio público nacional ou estrangeiro, contra princípios da administração pública ou contra os compromissos internacionais assumidos pelo Brasil, assim definidos:

I - prometer, oferecer ou dar, direta ou indiretamente, vantagem indevida a agente público, ou a terceira pessoa a ele relacionada;

II - comprovadamente, financiar, custear, patrocinar ou de qualquer modo subvencionar a prática dos atos ilícitos previstos nesta Lei;

III - comprovadamente, utilizar-se de interposta pessoa física ou jurídica para ocultar ou dissimular seus reais interesses ou a identidade dos beneficiários dos atos praticados;

IV - no tocante a licitações e contratos:

a) frustrar ou fraudar, mediante ajuste, combinação ou qualquer outro expediente, o caráter competitivo de procedimento licitatório público;

b) impedir, perturbar ou fraudar a realização de qualquer ato de procedimento licitatório público;

c) afastar ou procurar afastar licitante, por meio de fraude ou oferecimento de vantagem de qualquer tipo; d) fraudar licitação pública ou contrato dela decorrente; e) criar, de modo fraudulento ou irregular, pessoa jurídica para participar de licitação pública ou celebrar contrato administrativo;

f) obter vantagem ou benefício indevido, de modo fraudulento, de modificações ou prorrogações de contratos celebrados com a administração pública, sem autorização em lei, no ato convocatório da licitação pública ou nos respectivos instrumentos contratuais; ou

g) manipular ou fraudar o equilíbrio econômico-financeiro dos contratos celebrados com a administração pública; V - dificultar atividade de investigação ou fiscalização de órgãos, entidades ou agentes públicos, ou intervir em sua atuação, inclusive no âmbito das agências reguladoras e dos órgãos de fiscalização do sistema financeiro nacional. (BRASIL, 2013, on-line).
Conforme verificado nos dispositivos acima, a importância do monitoramento de condutas, por meio de controles internos, beneficia todos os setores da instituição, acarretando uma tendência mundial. Esses controles revelam muito mais do que uma tendência; mostram a direção que as instituições deverão seguir, para se prevenir no caso de descumprimento de normas internas ou jurídicas; imediatamente, pretende-se, de forma preventiva, elencar os riscos em áreas estratégicas.

Fica evidente, diante desse quadro, que a identificação antecipada por meio dos controles de riscos contra atos lesivos é uma necessidade para melhorar os resultados das empresas que pretendem contratar com o Governo. Espera-se, dessa forma, alcançar os padrões de ética e moral, como também as regulações pertinentes, para se alcançar um equilíbrio nas relações interdisciplinares; nesse ritmo, é apenas questão de tempo, de pouco tempo, para que a maioria das empresas estejam de acordo com as regras de conformidade, tornando-se um padrão nacional, nos requisitos de controle de riscos.

Vê-se, pois, que essa realidade será uma exigência normativa, para que as empresas possam proteger a sua reputação perante o mercado, bem como contratar com o governo, na previsão do artigo $7^{\circ}$, VIII. Por todas essas razões, tendo o compliance todos os seus controles e regras bem estabelecidos e funcionando, será muito produtivo o desenvolvimento das políticas de controles internos.

\section{NECESSIDADE DO PROGRAMA DE COMPLIANCE PARA CONTRATAR COM ENTES PÚBLICOS}

O Decreto no 8.420/2015, que regulamentou a Lei 12.846/2013 (Lei Anticorrupção), para ter um programa de conformidade efetivo, e não superficial, apenas para constar como documentação superficial da empresa, a partir desse momento, as empresas privadas terão que ter um programa de conformidade (compliance); dessa maneira todo o arco de sujeitos envolvidos nas transações empresariais público-privadas, 
agora terá que mostrar transparência em suas operações; o programa deve ter eficácia, com procedimentos claros e registros documentais.

Com o intento de gozar de interesses pessoais, utilizando como objeto os contratos com o Poder Público, causando assim, críticos problemas financeiros, resultado de atos lesivos causados pela corrupção devido a ações irresponsáveis, causando atos lesivos que são elencados no artigo $5^{\circ}$, com especial atenção aos incisos I, II e III:

Art. $5^{\circ}$ Constituem atos lesivos à administração pública, nacional ou estrangeira, para os fins desta Lei, todos aqueles praticados pelas pessoas jurídicas mencionadas no parágrafo único do art. 10, que atentem contra o patrimônio público nacional ou estrangeiro, contra princípios da administração pública ou contra os compromissos internacionais assumidos pelo Brasil, assim definidos:

I - prometer, oferecer ou dar, direta ou indiretamente, vantagem indevida a agente público, ou a terceira pessoa a ele relacionada;

II - comprovadamente, financiar, custear, patrocinar ou de qualquer modo subvencionar a prática dos atos ilícitos previstos nesta Lei;

III - comprovadamente, utilizar-se de interposta pessoa física ou jurídica para ocultar ou dissimular seus reais interesses ou a identidade dos beneficiários dos atos praticados. (BRASIL, 2013, on-line).

Este dispositivo, que estabelece práticas a serem verificadas com bastante atenção, em razão de não tipificar práticas ilícitas; desta forma, é relevante evitar posturas que possam ser interpretadas como atos e condutas irregulares.

A relação com o Poder Público, se difere da privada, por ser regida por vários princípios tais como os impressos no artigo 37 da Constituição Federal:

Art. 37. A administração pública, direta e indireta, de qualquer dos Poderes da União, dos Estados, do Distrito Federal e dos Municípios obedecerá aos princípios de legalidade, impessoalidade, moralidade, publicidade e eficiência. (BRASIL, 1988, on-line).

Os atos tipificados na Lei 12.846/2013 seguem em desarmonia com os princípios constitucionais, igualmente como particularidades da Lei 8.666/1993.
Assim, tanto os colaboradores e principalmente, a alta direção, devem fomentar o fortalecimento da cultura do compliance baseados na ética, com treinamentos periódicos, para reforças os padrões de conduta, por meio de um código de ética, possibilitar um canal para denúncias, e, assim, viabilizar o planejamento de tomadas de decisão, evitando riscos de prejudicar a imagem das instituições.

\section{CONCLUSÃO}

Conforme exposto acima, o que importa, portanto, é que o compliance evidência uma imensa contribuição, no que diz respeito à aplicação de controles das instituições, sendo eles internos, nos meios de procedimento jurídico, operacional e fiscal. Essa, porém, é uma tarefa que abarca todas as rotinas e os processos das entidades. Vê-se, pois, que esses controles fortalecem o cumprimento das normas e legislações. É preciso ressaltar que a cultura do compliance veio para ficar; infelizmente, muitos colaboradores não percebem dessa forma. Por final, estruturando os mecanismos de procedimento, que o resultam na prevenção de danos à imagem das entidades.

De modo geral, o programa de conformidade busca o equilíbrio em mitigar atos lesivos; preservar a imagem da entidade; conscientizar os colaboradores com treinamentos sobre manuais de conduta; deixando claro qual o propósito da entidade.

Ações adequadas para os procedimentos minimizam os riscos e podem diminuir problemas futuros, tanto na esfera judiciária quanto de forma administrativa, no seio da entidade; a infraestrutura correta para o canal de denúncia.

Estimula um exemplo a ser seguido pelos colaboradores e não celebra uma geração de acusações e incriminações; a comunhão dessas duas ferramentas de controle, tanto o manual de conduta quanto o canal de denúncias, devem ser acompanhadas pelo Comitê de Ética, pois, assim, se tem um acompanhamento e envolvimento da Alta Gestão, promovendo assim um melhor planejamento, para diminuir custos tributá- 
rios e demandas trabalhistas, assim como se pode ter uma perspectiva para futuros investimentos.

O Diploma Normativo Lei $12.846 / 2013$, que dispões sobre a responsabilização da pessoa jurídica por atos de corrupção, lesivos a Administração Pública no âmbito administrativo e civil, também prevê benevolência no cumprimento de penalidades sancionatórias para as empresas que têm programas de compliance como mecanismo de gerenciamento nas regulações internas.

Conclui-se, portanto, que é evidente os benefícios que a Lei 12.846/2013 vai guiar em um novo limiar para as contratações com o governo, tendo em vista que; pela perspectiva das empresas, ter um programa de compliance efetivo, com eficiência nos seus treinamentos, ativo para a comunicação de denúncias, regulações e manuais de procedimentos internos são o alicerce para conseguir contratar com o Governo, que por sua vez regulamenta compliance, como mecanismo para evitar atos de corrupção aos cofres Públicos.

Assim, resguardando o erário nacional e ainda vai nutrir com uma maior competência as diretrizes institucionais das empresas e seus mecanismos internos; mais ainda, o papel do Direito em ajudar o fortalecimento das instituições, promovendo uma cultura de ética nas empresas, reprimindo atos ilícitos e condutas corrupção, harmonizando a conduta das pessoas envolvidas na operação das empresas, buscando diminuir as condutas de risco nos negócios e preservando a imagem da empresa na presença do mercado.

\section{REFERÊNCIA}

BRASIL. Constituição da República Federativa do Brasil, de 5 de outubro de 1988. Diário Oficial da República Federativa do Brasil, Poder Executivo, Brasília-DF, 5 out. 1988. Disponível em: <http://www. planalto.gov.br/ccivil_03/constituicao/constituicao. htm>. Acesso em: 15 out. 2017.

BRASIL. Lei nº 8.666, de 21 de junho de 1993. Institui normas para licitações e contratos da
Administração Pública e dá outras providências, Brsilia-DF, jun. 1993. Disponível em: <http://www. planalto.gov.br/ccivil_03/leis/L8666cons.htm>. Acesso em: 15 out. 2017.

BRASIL. Lei no $\mathbf{1 2 . 8 4 6}$, de $1^{\circ}$ de agosto de 2013. Dispõe sobre a responsabilização administrativa e civil de pessoas jurídicas pela prática de atos contra a administração pública, nacional ou estrangeira, e dá outras providências, Brasili-DF, ago. 2013. Disponível em: <http://www.planalto.gov.br/ccivil_03/_ato20112014/2013/lei/l12846.htm>. Acesso em: 22 out. 2017.

BRASIL. Decreto n 8.420, de 18 de março de 2015. Dispõe sobre a responsabilização administrativa de pessoas jurídicas pela prática de atos contra a administração pública, nacional ou estrangeira e dá outras providências, Brasilia-DF, mar. 2015. Disponível em: <http://www.planalto.gov.br/ ccivil_03/_ato2015-2018/2015/decreto/D8420. htm>. Acesso em: 22 out. 2017

BRASIL. Lei Federal $\mathbf{n}^{\mathbf{0}} \mathbf{1 3 . 3 0 3}$, de 30 de junho de 2016. Dispõe sobre o estatuto jurídico da empresa pública, da sociedade de economia mista e de suas subsidiárias, no âmbito da União, dos Estados, do Distrito Federal e dos Municípios, Brasilia-DF, jun. 2016. Disponível em: <http://www.planalto.gov.br/ ccivil_03/_ato2015-2018/2016/lei/l13303.htm>. Acesso em: 2 nov. 2017.

BRASIL. Decreto no 8.945, de 27 de dezembro de 2016. Dispõe sobre o estatuto jurídico da empresa pública, da sociedade de economia mista e de suas subsidiárias, no âmbito da União, dos Estados, do Distrito Federal e dos Municípios, Brasilia-DF, 2016 Dez. Disponível em: <http://www.planalto.gov.br/ ccivil_03/_ato2015-2018/2016/decreto/D8945. htm>. Acesso em: 2 nov. 2017.

CICCO, Francesco de. Programas de compliance. A norma AS 3806: 2006: Compliance, AS 3806. São Paulo: Risk Tecnologia, 2008. 
CUNHA, Matheus. Lei impõe a adoção de programa de compliance nos contratos com entes públicos. LEC -

Legal Ethics Compliance. 25 out. 2017. Disponível em: <http://www.lecnews.com.br/blog/lei-impoe-a-adocaode-programa-de-compliance-nos-contratos-com-entespublicos/>. Acesso em: 26 out 2017.

MANSKE, Julio Max. Compliance anticorrupção programa de integridade - política de contratação de terceiros. phmp.com.br. 10 maio 2016. Disponível em: <http://phmp.com.br/artigos/complianceanticorrupcao-programa-de-integridade-politica-decontratacao-de-terceiros/> Acesso em: 1 nov. 2017

\section{MENDES, S.; CARVALHO, M.D. Compliance:} concorrência e combate à corrupção. São Paulo: Trevisan, 2017.
PEIXOTO, Ariosto Mila. Regulamentação exige programa de compliance específico e efetivo para empresas que vendem ao governo. Portal de Licitação. 17 mar. 2015. Disponível em: <http:// www.portaldelicitacao.com.br/site/artigos/ regulamentacao-exige-programa-de-complianceespecifico-e-efetivo-para-empresas-que-vendem-aogoverno-2/>. Acesso em: 24 out. 2017.

PESTANA, M. Lei anticorrupção: exame sistematizado da Lei 12846/2013. São Paulo: Manoel, 2016.

VIANNA, Simão, V.M. $\mathbf{O}$ acordo de leniência na lei anticorrupção: histórico, desafios e perspectivas. São Paulo: Trevisan, 2017. 